\title{
LAS ACCIONES DE GRUPO Y EL ARBITRAJE: UN DILEMA ENTRE CONSENTIMIENTO Y EFICIENCIA PROCESAL"
}

\author{
THE GROUP ACTIONS AND ARBITRAMENT: A DILEMA \\ BETWEEN CONSENT AND LABOUR EFFICIENCY
}

Álvaro Andrés Ramírez Huertas**:

\begin{abstract}
Resumen
El presente artículo tiene como objetivo demostrar que la posibilidad de tramitar acciones de clase a través de arbitraje genera una tensión muy fuerte entre el consentimiento - pilar fundamental del arbitrajey la eficiencia procesal que, como principio, subyace a la institución de las acciones de clase o grupo. Para tal efecto, se hace un análisis en torno a los pronunciamientos de distintas Cortes de los Estados Unidos en los que se discutió la procedencia de las acciones de grupo por medio de arbitraje, así como otros pronunciamientos existentes tanto en México como en Colombia, de los cuales se pueden extraer distintas conclusiones para enriquecer el entendimiento del arbitraje en Colombia y otras partes del mundo.
\end{abstract}

Recibido: 31 de enero de 2017 - Aprobado: 30 de noviembre de 2017.

* Artículo inédito.

Para citar el artículo: RAMÍREZ HUERTAS, Álvaro Andrés. Las acciones de grupo y el arbitraje: Un dilema entre consentimiento y eficiencia procesal. Revista del Instituto Colombiano de Derecho Procesal. No. 46 Julio - Diciembre. 2017, pp. 229-248.

El artículo fue el resultado de una investigación realizada para la ponencia en la Escuela Internacional de Arbitraje organizada por la Universidad Nacional de Colombia y la Universidad del Rosario, y que tuvo lugar entre el 16 y el 30 de enero de 2017.

* Abogado egresado de la Universidad Nacional de Colombia, con un Diploma en arbitraje nacional e internacional de la Cámara de Comercio de Bogotá, y un Diploma en Código General del Proceso de la Universidad Nacional de Colombia. Actualmente hace parte del equipo de litigios y arbitraje de Dentons Cárdenas \& Cárdenas. Contacto: aaramirezh@unal.edu.co 
Las acciones de grupo y el arbitraje: un dilema entre consentimiento y eficiencia procesal

Palabras clave: Arbitraje, acción de grupo, consentimiento.

\begin{abstract}
The purpose of this article is to demonstrate that class action arbitration generates a great tension between consent -as the cornerstone of arbitration- and the procedural efficiency underlying class or group actions. To this end, an analysis of different United States Courts' legal decisions discussing the admissibility of class actions in arbitration is carried out, as well as an analysis of some decisions in both Mexico and Colombia, from which different conclusions can be drawn for the enrichment of the understanding of arbitration in Colombia and worldwide.
\end{abstract}

Key words: Arbitration, class actions, consent.

\title{
Introducción ${ }^{1}$
}

El arbitraje colectivo o de clase, es una modalidad de arbitraje que adopta la forma típica de un procedimiento colectivo de tipo representativo como las acciones de clase (en los países del common law) o las acciones de grupo (en los países del civil law). En pocas palabras, se trata de una acción colectiva iniciada, mediante demanda arbitral, por uno o varios sujetos en representación de una pluralidad de cientos, tal vez miles, de individuos en condiciones similares.

El laudo arbitral que ponga fin a la controversia, podrá vincular bien sea a todos los miembros presentes (sistema "opt in") o a todos aquellos que no hayan expresado su deseo de ser excluidos del grupo o clase (sistema "opt out"). Naturalmente, para que proceda el arbitraje de clase será necesario que cada uno de los miembros de dicho grupo haya suscrito una cláusula compromisoria con la contraparte.

Sin embargo, la discusión surge toda vez que normalmente, cuando las partes pactan una cláusula compromisoria, están consintiendo en resolver determinadas controversias (alcance objetivo) con determinados sujetos (alcance subjetivo), razón por la cual la parte demandada podrá alegar que en ningún momento consintió en el arbitraje de clase, sino solamente en un arbitraje tradicional, en contra de una parte individual, tratando así de impulsar arbitrajes paralelos con cada uno de los miembros de la clase, desincentivando el uso de cualquier acción colectiva.

Un agradecimiento especial a la Dra. Eugenia Barraquer Sourdis, quien fungió como secretaria del tribunal arbitral que resolvió las controversias entre Luis Alberto Durán y Bancolombia, por la información suministrada en relación al caso. 
Poca atención se ha dedicado al estudio del arbitraje colectivo o de clase en Colombia, pese a la significativa atención que en los últimos años ha ganado en los Estados Unidos y en el estudio del arbitraje a nivel mundial. Inclusive, pocos son los países en los que existen sentencias judiciales o laudos arbitrales -al menos públicamente conocidos- que versen sobre dicha modalidad de arbitraje.

Sin embargo, Colombia puede considerarse una excepción. Mientras que en Estados Unidos la discusión tomó auge con la decisión de la Corte Suprema de Justicia en el caso Green Tree Financial v. Bazzle ${ }^{2}$, en el año 2003, nuestra Corte Suprema de Justicia ya había emitido un pronunciamiento equivalente en el $2001^{3}$.

El problema es que, mientras que en Estados Unidos la discusión ha seguido desarrollándose, en Colombia seguimos a la espera de más pronunciamientos -judiciales y arbitrales- que aborden el problema.

Por ello, el propósito del presente artículo es hacer un análisis de los distintos avances existentes a nivel internacional (Estados Unidos, México, entre otros) en materia de arbitraje colectivo o de clase, los cuales se constituyen como insumos importantes para los futuros pronunciamientos que hayan de tener lugar en nuestro país.

\section{La experiencia americana en materia de arbitraje de clase}

En Estados Unidos, la posibilidad de tramitar una acción de clase por medio de arbitraje fue aceptada desde la década de 1980, principalmente en las Cortes de California, en aquellos casos en los que surgían reclamaciones por parte de un número plural de individuos que se consideraban afectados por los actos de una entidad con la cual habían celebrado un contrato de adhesión, en el que se había incluido una cláusula compromisoria ${ }^{4}$.

Así, por ejemplo, en Keating v. Superior Court ${ }^{5}$ la Corte Suprema de California se enfrentó a una controversia entre Southland Corporation, propietario y

2 Estados Unidos. Corte Suprema de Justicia. Green Tree Financial Corp. v. Bazzle. 23 de junio de 2003. No. 02-634.

3 Colombia. Tribunal de Arbitramento Luis Alberto Durán Valencia v. Bancolombia S.A., Portafolio de Inversiones Suramericana S.A., Cementos del Valle S.A., Compañía Colombiana de Tabaco S.A., Compañía de Cementos Argos S.A., Inversiones Reacol S.A., Compañía Suramericana de Seguros S.A. y Suramericana de Inversiones S.A. Auto No. 3 del 17 de febrero de 2003.

4 STRONG, Stacie. "Collective arbitration under the DIS supplementary rules for corporate law disputes". En: ASA Bulletin. Vol. 29. No. 1. Ginebra: Asociación Suiza del Arbitraje, 2011, pp. 145-165.

5 Estados Unidos. Corte Suprema de Justicia de California. Keating v. Superior Court. 10 de junio de 1982. 31 Cal. 3d 584. 
Las acciones de grupo y el arbitraje: un dilema entre consentimiento y eficiencia procesal

franquiciado de las tiendas de conveniencia 7-Eleven, y una pluralidad de franquiciantes de dichas tiendas con cada uno de los cuales había celebrado un contrato de franquicia contentivo de una cláusula compromisoria, quienes iniciaron una acción de clase ante las cortes estatales alegando el incumplimiento del contrato y en consecuencia solicitando una indemnización de perjuicios.

Dada la existencia de la cláusula compromisoria en cada uno de los contratos individuales de franquicia, la empresa Southland Corporation solicitó que las partes fueran remitidas a arbitraje para resolver sus controversias, lo cual fue aceptado por la Corte de Juicio (Trial Court), razón por la cual los franquiciantes solicitaron ante la Corte Suprema de California que se ordenara que el arbitraje se adelantara en la modalidad de una acción de clase.

La Corte Suprema de Justicia resolvió revocar la decisión de la Corte de Juicio, al considerar que resultaba necesario permitir las acciones de clase en el arbitraje, pues de lo contrario la sola inclusión de una cláusula compromisoria en un contrato de adhesión tendría el potencial de eliminar las acciones de clase de plano, pues cada uno de los sujetos que pudiera verse afectado por las actuaciones antijurídicas de su co-contratante, se vería obligado a acudir a un proceso arbitral individual:

"Si el derecho a un procedimiento de clase pudiera ser automáticamente eliminado en relaciones gobernadas por contratos de adhesión a través de la inclusión de una cláusula de arbitraje, el potencial para restar valor a los principios de dichas acciones de clase, y para paralizar la protección efectiva a los intereses de un grupo, sería sustancial. Los procesos arbitrales bien pueden proveer ciertas ventajas a través de la reducción de tiempo y gastos; pero, dependiendo en la naturaleza de los asuntos y las pruebas que se presenten, es por lo menos dudoso que dichas ventajas puedan compensar la injusticia inherente a forzar a cientos o quizás miles de individuos con reclamaciones que involucran cuestiones comunes de hecho y de derecho a litigarlas en procedimientos separados en contra de una parte con recursos

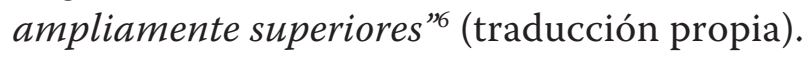

Para la Corte Suprema de California, en consecuencia, la discusión acerca de la procedencia de las acciones de clase por medio de arbitraje se limitó a una cuestión de alternativas, de tal manera que negar de plano la procedencia de las acciones de clase en el arbitraje sería equivalente a forzar a cientos o miles de individuos a litigar separadamente sus controversias, con la carga financiera que ello supone, lo cual inclusive podría dar lugar a que las reclamaciones de dichos individuos queden en la impunidad cuando quiera que el monto en disputa no sea lo suficientemente significativo para compensar los gastos inherentes a un trámite arbitral.

$6 \quad$ Ibid. 
No obstante, uno de los jueces de la Corte Suprema de California (Juez Richardson) expresó una opinión disidente, según la cual, debido a la naturaleza consensual del arbitraje, cuando quiera que las cláusulas arbitrales en cuestión no establezcan la procedencia de una acción de clase, no podrá imponérsele a las partes dicho tipo de procedimiento, más aún cuando en su concepto:

"Los procedimientos de clase tenderian a hacer el arbitraje ineficiente en lugar de eficiente, lento en lugar de expedito, y procedimental en lugar de informal..." (traducción propia).

Y para efectos de abordar la posible eliminación de los procedimientos colectivos por medio de la inclusión de una cláusula arbitral en contratos de adhesión, el Juez Richardson manifestó que:

"En un caso en el que los procedimientos de clase provean el único método económico de presentar una demanda, existe una alternativa que protegería tanto la integridad contractual de un acuerdo arbitral como los intereses de los demandantes individuales. Una solución que ha sido sugerida, y que la mayoría rechaza, "sería sostener que el acuerdo arbitral contenido en contratos de adhesión no puede operar para suspender acciones de clase adecuadamente sostenibles". Estoy de acuerdo en que como regla general dicha posición sería contraria al acuerdo arbitral de las partes y a la politica de favorecimiento al arbitraje. Existe, sin embargo, otra alternativa" ${ }^{8}$ (traducción propia), (subrayado fuera de texto).

Dicha alternativa, en criterio del Juez Richardson, sería inaplicar los acuerdos arbitrales, cuando quiera que permitan a la parte económicamente fuerte escapar a la responsabilidad civil derivada de sus actos.

En pocas palabras, mientras que para la Corte Suprema de California la única alternativa viable en presencia de una cláusula compromisoria es permitir el arbitraje de clase, para el Juez Richardson la alternativa que no sacrificaría el consentimiento de las partes, así como la celeridad e informalidad del arbitraje, sería inaplicar las cláusulas arbitrales en cuestión.

Fue necesario que pasaran veinte años para que el arbitraje de clase dejara de ser aceptado solamente por las Cortes de California y adquiriera, por el contrario, una dimensión nacional, esta vez en relación a unos contratos de mutuo celebrados por la entidad financiera Green Tree Financial con distintos individuos, dentro de los que se encontraban Lynn W. Bazzle y Burt A. Bazzle, quienes decidieron iniciar una acción de clase en contra de la entidad financiera alegando que la ausencia de información sobre preferencia de abogados y agentes de seguros era contraria al Código de Protección al Consumidor de Carolina

Ibid.

Ibíd. 
Las acciones de grupo y el arbitraje: un dilema entre consentimiento y eficiencia procesal

del Sur y, en consecuencia, habían sufrido perjuicios. Al mismo tiempo, los ciudadanos Daniel B. Lackey, George Buggs y Florine Buggs decidieron iniciar una acción de clase idéntica bajo la misma clase de contratos de mutuo.

En ambos casos, los contratos contenían una cláusula compromisoria, razón por la cual Green Tree Financial solicitó ante las Cortes que las partes fueran remitidas a arbitraje. Las solicitudes prosperaron, y en consecuencia se prosiguió a la constitución de dos tribunales arbitrales, los cuales se declararon competentes para conocer de las acciones y dictaron, cada uno, un laudo arbitral en el que condenaban a la entidad financiera al pago de perjuicios irrogados a todos aquellos consumidores que se encontraran en la misma situación de los demandantes y no hubieran expresado su voluntad de ser excluidos del grupo.

Los dos laudos arbitrales fueron confirmados por una Trial Court, cuya decisión fue apelada por Green Tree Financial ante la Corte Suprema de Justicia de Carolina del Sur, la cual decidió consolidar los procedimientos para emitir una única decisión.

Al efectuar el análisis de la controversia, la Corte reconoció que los acuerdos arbitrales en cuestión guardaban absoluto silencio en relación a la procedencia de la acción de clase por medio de arbitraje, pese a lo cual manifestó que:

"Hoy, adoptamos el acercamiento adoptado por las cortes de California en Keating y Blue Cross, y sostenemos que el arbitraje de clase puede ser ordenado cuando el acuerdo arbitral es silente si ello sirve a la eficiencia $y$ a la equidad, y no resulta en ningún perjuicio. Si ejecutamos una cláusula arbitral adhesiva, pero prohibimos las acciones de clase en el arbitraje cuando el acuerdo es silente, la parte redactora podría efectivamente evitar acciones de clase en su contra sin tener que decirlo en el acuerdo" (traducción propia).

Como consecuencia de lo anterior, la Corte Suprema de Justicia de Carolina del Sur resolvió confirmar los laudos arbitrales. Sin embargo, Gree Tree Financial presentó un "writ of certiorari" ante la Corte Suprema de Justicia de Estados Unidos, para que revisara si la decisión de la Corte Federal se ajustaba o no a derecho.

La Corte Suprema de Justicia no solamente decidió examinar la controversia, sino que además revocó la decisión de la Corte Suprema de Carolina del Sur al considerar que esta autoridad, al haberse pronunciado sobre la procedencia de las acciones de clase por medio de arbitraje, había invadido una competencia propia del tribunal arbitral. Por ello, la Corte afirmó:

9 Estados Unidos. Corte Suprema de Carolina del Sur. Lynn W. Bazzle and Burt A. Bazzle, in a representative capacity on behalf of a class and for all others similarly situated v. Green Tree Financial Corp. - Daniel B. Lackey, George Buggs and Florine Buggs, in a representative capacity on behalf of a class and for all others similarly situated v. Green Tree Financial Corp. 26 de agosto del 2002. No. 25523. 
"La pregunta aquí no encuadra en las limitadas circunstancias bajo las cuales las cortes pueden asumir que las partes quisieron que las cortes, no los árbitros, decidieran un asunto particular relacionado con el arbitraje, en tanto no concierne ni a la validez de la cláusula arbitral ni a su aplicación a la controversia en cuestión. La pregunta relevante aquí es qué tipo de procedimiento arbitral las partes acordaron, la cual no versa sobre una ley estatal o a un proceso judicial, sino sobre la interpretación del contrato y el procedimiento arbitral. Los árbitros están bien situados para responder esa pregunta"10 (traducción propia).

Nótese, entonces, que la Corte Suprema de Justicia ratificó el principio de kompetenz-kompetenz para efectos de analizar la procedencia de las acciones de clase en el arbitraje, razón por la cual inmediatamente después de la decisión en Green Tree Financial v. Bazzle, dos de los centros de arbitraje más importantes de Estados Unidos -la Asociación Americana de Arbitraje (AAA) y la Judicial and Mediation Services (JAMS) - expidieron unas reglas de arbitraje en virtud de las cuales se pudieran tramitar este tipo de controversias.

Naturalmente, el número de procesos arbitrales de clase comenzó a aumentar, y los tribunales arbitrales de forma consistente y reiterada empezaron a declararse competentes para conocer acciones de clase argumentando que la amplia redacción de los acuerdos arbitrales (típicamente la redacción de "cualquier controversia derivada de este contrato o relacionada con el mismo será resuelta por medio de arbitraje") era un indicador de que las partes efectivamente consintieron en el arbitraje de clase.

Sin embargo, una decisión posterior de la Corte Suprema de Justicia de Estados Unidos, en el año 2010, cambió radicalmente el panorama del arbitraje de clase en el país angloparlante. Se trató del caso Stolt-Nielsen v. AnimalFeeds ${ }^{11}$, en el que la empresa de alimentos AnimalFeeds International Corp. decidió iniciar una acción de clase en contra de distintas empresas de transporte marítimo, toda vez que las mismas habían celebrado un acuerdo de fijación de precios a partir del cual se ocasionaron perjuicios a sus clientes.

Las partes en cuestión habían celebrado un contrato de fletamento (charter party) que incluía una cláusula compromisoria, con la típica redacción amplia en virtud de la cual los tribunales arbitrales constituidos bajo las reglas de la AAA venían declarándose competentes.

Inicialmente, la acción de clase fue conocida por una Corte de Distrito en Connecticut, ante la cual Stolt-Nielsen alegó la existencia de una cláusula

10 Estados Unidos. Corte Suprema de Justicia. Green Tree Financial Corp. v. Bazzle. 23 de junio de 2003. No. 02-634.

11 Estados Unidos. Corte Suprema de Justicia. Stolt-Nielsen, et. al. v. AnimalFeeds. 27 de abril de 2010. No. 08-1198. 
Las acciones de grupo y el arbitraje: un dilema entre consentimiento y eficiencia procesal

compromisoria. Finalmente, las partes fueron remitidas a arbitraje, el cual fue administrado bajo las Reglas Suplementarias de Arbitraje de Clase de la AAA. Una vez constituido el Tribunal Arbitral, el mismo decidió declararse competente pese a que las cláusulas compromisorias en cuestión eran completamente silentes en torno a la procedencia de las acciones de clase en el arbitraje, por lo cual dictó un laudo parcial y suspendió el procedimiento arbitral para que la parte interesada buscará la anulación del laudo ante las cortes estatales.

Stolt-Nielsen solicitó ante la Corte del Distrito Sur de Nueva York la anulación del laudo, la cual efectivamente lo anuló al considerar que el tribunal arbitral había incurrido en un desconocimiento manifiesto del derecho. En sede de apelación, la Corte de Apelaciones para el Segundo Circuito resolvió revocar la anterior decisión, por lo cual Stolt-Nielsen interpuso "writ of certiorari" ante la Corte Suprema de Estados Unidos para que revisara la decisión de segunda instancia. La Corte aceptó la solicitud de revisión, y manifestó lo siguiente:

"Desafortunadamente, sin embargo, tanto las partes como el panel arbitral parecen haber malentendido el caso Bazzle en otro sentido, a saber, que estableció el estándar a ser aplicado por el juzgador para determinar si un contrato puede ser interpretado para permitir el arbitraje de clase (...)

Como hemos explicado, sin embargo, el caso Bazzle no estableció la regla a ser aplicada para decidir si el arbitraje de clase está permitido. La decisión en Bazzle dejó esa pregunta abierta, la cual será respondida en esta ocasión"12 (traducción propia).

Ahora bien, ¿por qué razón la Corte manifestó que en el caso Green Tree Financial v. Bazzle no se establecieron los estándares para determinar si una acción de clase es o no procedente por medio de arbitraje? En opinión de la misma Corte, ello se debió a que la Corte Suprema de Justicia se limitó a decir que correspondía al árbitro decidir sobre dicha procedencia, sin especificar los criterios a aplicar a tal respecto. En pocas palabras, la Corte reconoció que su decisión anterior se limitaba a ratificar el principio de kompetenz-kompetenz.

Con todo, la Corte Suprema de Justicia sentó el criterio definitivo, que sería seguido en pronunciamientos posteriores, y que permite determinar cuándo es procedente una acción de clase por medio de arbitraje, en los siguientes términos:

“... una parte no puede ser obligada bajo la FAA a someterse a arbitraje de clase salvo que exista una base contractual que permita concluir que las partes acordaron en tal sentido"13 (traducción propia).

A partir de lo anterior, no basta entonces con que exista un acuerdo arbitral entre cada uno de los miembros de la clase y el demandado, sino que será

12 Ibid., pp. 15-17.

13 Ibid. 
necesario además que exista una base contractual adicional de la cual se pueda inferir que las partes efectivamente contemplaron la posibilidad de someterse a un arbitraje de clase.

Lo anterior, toda vez que:

“... el arbitraje de clase cambia la naturaleza del arbitraje a tal grado que no puede presumirse que las partes lo consintieron al haber simplemente acordado someter sus disputas a un árbitro"lit (traducción propia).

La similitud entre la opinión de la Corte Suprema de Justicia de Estados Unidos en el caso Stolt-Nielsen v. AnimalFeeds y la opinión disidente del Juez Richardson en el caso Keating v. Superior Court es evidente, pues en ambos casos se presume que el consentimiento de las partes para acudir a arbitraje se fundamenta en expectativas de eficiencia, celeridad e informalidad, todo lo cual se pierde en tratándose de acciones de clase que, además de sacrificar la confidencialidad inherente al proceso arbitral, implican un mayor grado de intervención judicial.

No obstante, a diferencia de la opinión disidente del Juez Richardson, la decisión en Stolt-Nielsen v. AnimalFeeds no ofrece ninguna alternativa distinta al arbitraje individual, por lo cual podría decirse que bajo su ratio descidendi los miembros de determinada clase que hayan suscrito un acuerdo arbitral se verían forzados a litigar separadamente sus controversias, con la eventual consecuencia de que la parte redactora de los contratos en cuestión pueda escapar a las acciones de clase.

Con todo, hay algunas preguntas que vale la pena formular, a saber: ¿cuál puede ser la base contractual requerida para el arbitraje de clase?, ¿se necesita un acuerdo expreso para que proceda el arbitraje de clase en Estados Unidos? Para ello, resulta ilustrativo el caso Oxford Health Plans v. Sutter ${ }^{15}$ del año 2013.

En dicho caso, John Sutter, un pediatra que había celebrado un contrato con Oxford Health Plans en virtud del cual se comprometía a proveer tratamiento médico a los miembros de la compañía a cambio de una contraprestación en dinero, decidió iniciar una acción de clase en la Corte Superior de Nueva Jersey, alegando la falta de pago de la respectiva contraprestación. El contrato en cuestión contenía una cláusula arbitral según la cual:

"Ninguna acción civil relativa a cualquier disputa que surja bajo este Acuerdo será iniciada ante cualquier corte, y todas las disputas en cuestión serán sometidas a arbitraje final y obligatorio en Nueva Jersey, de conformidad

$14 \quad$ Ibid., p. 21.

15 Estados Unidos. Corte Suprema de Justicia. Oxford Health Plans LLC v. Sutter. 10 de junio de 2013. No. 12-135. 
Las acciones de grupo y el arbitraje: un dilema entre consentimiento y eficiencia procesal

con las reglas de la Asociación Americana de Arbitraje con un solo árbitro" (traducción propia).

Como es natural, Oxford Health Plans alegó la existencia de una cláusula compromisoria y solicitó que las partes fueran remitidas a arbitraje. Una vez constituido el Tribunal Arbitral, este enfocó su análisis en torno a la procedencia de la acción de clase por medio de arbitraje desde la perspectiva de la redacción de la cláusula arbitral misma, a partir de lo cual concluyó que en la medida en que la acción de clase es una "acción civil", se podía evidenciar que las partes habían consentido en el arbitraje de clase.

Inconforme con dicha decisión, Oxford Health Plans solicitó la anulación del laudo arbitral, la cual finalmente no prosperó, y posteriormente acudió ante la Corte Suprema de Justicia de Estados Unidos para que ésta revisara las decisiones judiciales que confirmaron el laudo arbitral. Frente a ello, la Corte Suprema de Justicia confirmó las decisiones adoptadas por los jueces inferiores, al encontrar que:

"La diferencia con este caso es clara. En Stolt-Nielsen, los árbitros no interpretaron el contrato de las partes, y no identificaron algún acuerdo que autorizara los procedimientos de clase. Por ello al anular la decisión arbitral, encontramos que ellos no malinterpretaron el contrato, sino que abandonaron su rol interpretativo. Aquí, el árbitro interpretó el contrato (enfocándose, como es usual, en su lenguaje), y encontró un acuerdo para permitir el arbitraje de clase 16 (traducción propia).

Lo anterior significa, entonces, que la redacción misma del acuerdo arbitral es la que puede proveer la base contractual requerida bajo Stolt-Nielsen $v$. AnimalFeeds para la procedencia del arbitraje de clase, de tal manera que se requiere una amplitud especial del acuerdo para tal efecto. Sin dicha base contractual, no habrá arbitraje de clase.

Sin embargo, es evidente que desde el caso Stolt-Nielsen v. AnimalFeeds la discusión en torno al arbitraje de clase en Estados Unidos ha sido contemplada desde una óptica exclusivamente contractual, y que desaparecieron completamente los análisis de costo-beneficio y de eficiencia procesal que eran el núcleo central de las decisiones judiciales hasta Bazzle, sin que sea claro hasta qué punto las posición de la jurisprudencia americana está obligando a cientos o miles de individuos a litigar sus controversias separadamente o, inclusive, a no demandar en absoluto, más aún cuando las empresas que redactan los contratos han empezado a incluir renuncias expresas al arbitraje de clase (class-arbitration waivers) ${ }^{17}$.

$16 \quad$ Ibid., p. 7.

17 GUTH BARNES, Lauren. "How mandatory arbitration agreements and class action waivers undermine consumer rights and why we need congress to act". En: Harvard Law \& Policy Review. Vol. 9. No. 1. Cambridge: Estados Unidos, 2015. pp. 329-354. 
Por ello, puede decirse que el análisis del arbitraje de clase en Estados Unidos se ha inclinado por una perspectiva contractual basada en el supuesto según el cual las acciones de clase "desnaturalizan" el arbitraje, por lo cual se requiere un consentimiento cualificado para tal efecto, dejando a un lado las preocupaciones relativas a la eficiencia procesal y la posible eliminación de las acciones colectivas mediante la inclusión de cláusulas arbitrales en contratos masivamente celebrados con el público.

\section{La experiencia mexicana en materia de arbitraje de clase}

A diferencia de Estados Unidos, México no cuenta con un gran número de casos judiciales en los que se haya discutido la compatibilidad de las acciones de clase y el arbitraje. Sin embargo, si existe una sentencia que reviste especial relevancia teniendo en cuenta las conclusiones que se derivan de la experiencia estadounidense en la materia.

Para el año 2013, el Juzgado Tercero de Distrito en el Estado de Guerrero (México) se enfrentó a una controversia relativa a una colectividad conformada por sesenta y dos adquirentes de membresías de un club de golf, los cuales iniciaron una acción de clase en contra de la empresa en cuestión alegando una deficiente prestación del servicio y unas modificaciones unilaterales de los contratos a partir de las cuales sufrieron unos perjuicios. El contrato de membresía incluía una cláusula compromisoria según la cual:

"Todas las controversias surgidas entre las partes en relación con lo anterior serán resueltas definitivamente mediante arbitraje celebrado con arreglo a las disposiciones contenidas en las Normas del Centro de Arbitraje de México ("CAM") y presidido por un único árbitro designado de conformidad con dichas normas (...)".

Dadas las alegaciones de la parte demandada en torno a la existencia de la cláusula compromisoria, el Juez de Distrito resolvió declararse incompetente para conocer la acción de clase, decisión que fue confirmada en segunda instancia. Debido a lo anterior, la colectividad decidió interponer una acción de amparo directamente ante la Corte Suprema de Justicia de la Nación (CSJN).

Mediante sentencia del 24 de septiembre de $2014^{18}$, la CSJN decidió amparar los derechos de la colectividad y, en su lugar, remitir a las partes a la justicia ordinaria para que se surtiera el trámite de la acción colectiva, pues en su sentir si una autoridad judicial pudiera declararse incompetente para conocer una acción de clase en presencia de una cláusula compromisoria, entonces ello:

18 México. Corte Suprema de Justicia de la Nación. Amparo directo 33/2014. 24 de septiembre de 2014. 
Las acciones de grupo y el arbitraje: un dilema entre consentimiento y eficiencia procesal

“(...) implicaría aplicar rigurosamente disposiciones ordinarias mercantiles y civiles, y pasar por alto que estamos ante una relación de consumo, la cual se regula por normas constitucionales y legales de orden público que son irrenunciables. Ello también privaría a la colectividad de consumidores de ciertos beneficios en concreto que buscan obtener con la promoción de una acción colectiva y los cuales no se pudieran conseguir con el trámite de procedimientos individuales" ${ }^{\prime 19}$ (subrayado fuera de texto).

Como puede apreciarse, el anterior pronunciamiento se sustenta en distintas premisas, a saber: (i) la cláusula compromisoria en cuestión solamente consagraba la posibilidad de un procedimiento arbitral individual entre cada miembro del club de golf y la entidad patrocinadora; (b) debido a lo anterior, someter a las partes a arbitraje significaría privarlas de la posibilidad de adelantar una acción colectiva, lo cual (c) sería contrario a los derechos de los consumidores.

No obstante, la decisión de la CSJN deja algunas preguntas abiertas en materia de arbitraje, como, por ejemplo: ¿qué sucede con el principio de kompetenz-kompetenz?, ¿no les correspondía a los árbitros, en primer lugar, la competencia para declarar su propia competencia como lo declaró la Corte Suprema de Justicia de Estados Unidos en el caso Green Tree Financial v. Bazzle?

Al respecto, debe decirse que el artículo 1424 del Código de Comercio Mexicano consagra que:

"El juez al que se someta un litigio sobre un asunto que sea objeto de un acuerdo de arbitraje, remitirá a las partes al arbitraje en el momento en que lo solicite cualquiera de ellas, a menos que se compruebe que dicho acuerdo es nulo, ineficaz o de ejecución imposible". (subrayado fuera de texto).

Bajo la sentencia de la CSJN no queda claro si la cláusula arbitral en cuestión fue declarada nula, ineficaz o de ejecución imposible. Lo que si queda claro es que la autoridad judicial estableció en cualquier caso una excepción al principio de kompetenz-kompetenz, en aras a evitar la eliminación de las acciones colectivas mediante la inclusión de cláusulas arbitrales en los contratos de consumo.

\section{La experiencia colombiana en materia de arbitraje de clase}

Mientras que en Estados Unidos la discusión en torno al arbitraje de clase tomó auge con la decisión de la Corte Suprema de Justicia en el caso Green Tree Financial v. Bazzle, en el año 2003, nuestra Corte Suprema de Justicia ya había emitido un pronunciamiento equivalente en el 2001.

En efecto, para el año 2001, la Corte Suprema de Justicia de Colombia se enfrentó a la controversia surgida con ocasión del proceso de fusión por absorción

$19 \quad$ Ibid., p. 32. 
que se adelantó por parte del Banco Industrial Colombiano S.A. respecto del Banco de Colombia S.A., dando lugar a la sociedad Bancolombia S.A.

En particular, algunos accionistas minoritarios alegaron que el Banco Industrial Colombiano S.A. y el Banco de Colombia S.A., a través de unos acuerdos implícitos, desconocieron las normas reguladoras del mercado público de valores, por lo cual demandaron la indemnización de perjuicios ante el Juzgado Veinte Civil del Circuito de Bogotá.

En los estatutos de Bancolombia S.A. se había pactado una cláusula compromisoria, del siguiente tenor:

"Las diferencias que ocurran a los accionistas con el Banco, o a los accionistas entre sí, por razón de su carácter de tales, durante el contrato social, al tiempo de disolverse el Banco y en el periodo de liquidación, serán sometidas a la decisión obligatoria de un Tribunal de Arbitramento que funcionará en la ciudad de Bogotá, Colombia y estará integrado por tres (3) ciudadanos colombianos en ejercicio de sus derechos civiles y abogados, los cuales fallaran en derecho".

En razón a ello, la entidad demandada interpuso la excepción de cláusula compromisoria, la cual fue amparada por el Juzgado, el cual decidió entonces remitir a las partes a arbitraje ante la Cámara de Comercio de Bogotá.

Inconforme con dicha decisión, los accionistas demandantes interpusieron acción de tutela en contra de la providencia del Juez del Circuito, la cual fue resuelta desfavorablemente por el Tribunal Superior del Distrito Judicial de Bogotá cuya decisión a su vez fue impugnada ante la Corte Suprema de Justicia.

Mediante sentencia del 11 de mayo de $2001^{20}$, la Corte Suprema de Justicia decidió confirmar la decisión del Tribunal Superior de Bogotá, al considerar que la decisión de remitir a las partes a arbitraje se encontraba ajustaba a derecho, toda vez que:

"cabe afirmar que los Tribunales de arbitramento, si bien pueden conocer de pretensiones dirigidas a obtener la reparación de un daño individual, como que se trata de un asunto transigible, no son competentes, por regla, para conocer de las acciones de grupo o de clase, pero no porque éstas tengan consagración constitucional, pues todo proceso la tiene-incluso el tramitado ante los árbitros (inc. 4 art. 116 C. Pol.)-, sino porque la sentencia que en ellas se profiera, por lo menos en Colombia, vincula a todas las personas que se encuentran en "condiciones uniformes respecto de una misma causa que originó perjuicios individuales" y que, por lo mismo, pertenecen al grupo interesado en el resarcimiento del perjuicio.

(...)

20 Colombia. Corte Suprema de Justicia. Sentencia del 11 de mayo de 2011. Exp. 1100122030002001-0183-01. MP. Carlos Ignacio Jaramillo Jaramillo. 
Las acciones de grupo y el arbitraje: un dilema entre consentimiento y eficiencia procesal

Otra, en sana lógica, parecería ser la conclusión cuando el "grupo" únicamente esté conformado por personas que, como los socios de una sociedad, han concertado el pacto arbitral o aceptado la presencia de una cláusula compromisoria-, pues en tal hipótesis, que es la que aqui se presenta, justamente todos los integrantes de aquella y posibles perjudicados con una acción u omisión de otro accionista o de la sociedad, relacionada con el contrato social, ya han renunciado, ab initio, a ventilar sus pretensiones ante los Jueces, de suerte que si alguno de ellos solicitara la exclusión del grupo para hacer valer su derecho en proceso separado, éste también tendría que promoverse ante árbitros" ${ }^{\prime 21}$.

Sin embargo, las afirmaciones de la Corte Suprema de Justicia no pueden considerarse como una aceptación incondicional del arbitraje de clase, toda vez que en la misma sentencia la Corte manifestó que:

“(...) téngase en cuenta que la Corte - en la esfera constitucional supraindicadano puede tomar partido por alguna de las tesituras expuestas, pues de alguna manera ello podría comprometer in eventum la decisión que le correspondería adoptar al Tribunal de Arbitramento que se llegase a convocar, quien deberá resolver "sobre su competencia" en la primera audiencia de trámite (nral. 2 art. 124 Ley 446/98; nral. 2 art. 147 Dec. 1818/98). Por tanto, stricto sensu, la censura que se hace a este respecto también luce pretemporánea, dado que los árbitros aún no se han pronunciado sobre la materia. Tan sólo lo han hecho los Jueces del Estado, cuya determinación no vincula a aquellos, quienes - según las circunstancias-bien podrían declinar el conocimiento de la acción de grupo que se les proponga, precisamente si concluyen, soberanamente, que no son competentes para conocer de ese tipo de acciones, o que la cláusula compromisoria no comprende el asunto litigado" ${ }^{22}$ (subrayado fuera de texto).

En pocas palabras, nuestra Corte Suprema de Justicia, aplicó cabalmente el principio de kompetenz-kompetenz, dejando en cabeza de los árbitros la decisión en torno a la procedencia de las acciones de clase por medio de arbitraje. Pero, las circunstancias concretas del caso, esto es, la presencia no de una multiplicidad de contratos con cláusula arbitral, sino de unos únicos estatutos sociales con una única cláusula arbitral, llevaron al Tribunal Arbitral a declararse competente y aceptar la procedencia del arbitraje de clase en los siguientes términos:

"Las reglas incluidas en el contrato social, como lo señaló claramente la sentencia de la Corte de 11 de mayo del 2001, se extienden a todos los socios o accionistas, con independencia de que las hayan votado favorablemente o no y así se trate de socios o accionistas posteriores a la respectiva estipulación. Habiéndose todos ellos sometido en forma previa a las reglas de la democracia societaria, todos ellos corren con las consecuencias de las decisiones válidamente adoptadas. No choca contra lo anterior la circunstancia de que

$\overline{21}$ Ibid., pp. 16-17.

$22 \quad$ Ibíd., p. 24.

242 Revista del Instituto Colombiano de Derecho Procesal • No. 46 
una cláusula compromisoria haya sido adoptada con posterioridad a hechos en los cuales se funda una reclamación, en tanto la ley, con fundamento en el artículo 116 de la Carta, establece la habilitación de los árbitros derivada de la voluntad de las partes, sin especificar si esta habilitación es anterior o posterior a las diferencias o a la fuente de ellas" ${ }^{\prime 23}$.

Nótese que la discusión no consistió en la procedencia o improcedencia del arbitraje de clase desde el punto de vista del consentimiento, pues al tratarse de un contrato de sociedad todos los accionistas que acudieron ante el Tribunal conjuntamente en grupo habían consentido en una única cláusula compromisoria, sino particularmente sobre la aplicabilidad de la cláusula compromisoria al haber sido adoptada con posterioridad a los hechos materia de reclamación.

Debido a lo anterior, puede decirse que la decisión en el caso Luis Alberto Durán v. Bancolombia es equivalente en su ratio descidendi al caso Green Tree Financialv. Bazzle, pues en ambos casos se ratifica el principio de kompetenz-kompetenz. Pero, a diferencia de este último, en Luis Alberto Durán v. Bancolombia se sienta un criterio especial en materia de acciones colectivas derivadas del contrato de sociedad, en las cuales la existencia de un único consentimiento entre todos los accionistas y la sociedad es incontrovertible, quedando abierta la pregunta en torno a la procedencia de las acciones de clase por medio de arbitraje cuando se trata de una multiplicidad de contratos celebrados por una misma persona con distintos individuos.

\section{Análisis comparativo de la experiencia americana, mexicana y colombiana en materia de arbitraje de clase}

Son muchas las conclusiones que uno podría extraer de los casos anteriormente analizados, pero para efectos de facilidad metodológica dividiremos el análisis en tres grandes preguntas: (i) ¿es posible tramitar acciones de clase por medio de arbitraje?, (ii) ¿en qué condiciones debe declararse competente un tribunal arbitral frente a una acción de clase?, y (iii) ¿es más eficiente tramitar una acción de clase ante un tribunal arbitral que ante un juez estatal?

\section{1 ¿Es posible tramitar acciones de clase por medio de arbitraje?}

La experiencia internacional nos muestra que en efecto es posible. Al respecto, la experiencia americana es bastante clara en indicar que no bastará con la

23 Colombia. Tribunal de Arbitramento Luis Alberto Durán Valencia v. Bancolombia S.A., Portafolio de Inversiones Suramericana S.A., Cementos del Valle S.A., Compañía Colombiana de Tabaco S.A., Compañía de Cementos Argos S.A., Inversiones Reacol S.A., Compañía Suramericana de Seguros S.A. y Suramericana de Inversiones S.A. Auto No. 3 del 17 de febrero de 2003. 
presencia de una cláusula compromisoria común y corriente para la procedencia de las acciones de clase por medio de arbitraje. Será necesario que exista una "base contractual" de la cual pueda inferirse que las partes efectivamente así lo quisieron. Lo mismo puede predicarse de Colombia y México.

Sin embargo, es necesario hacer una precisión. En tratándose de una pluralidad de contratos en los que se haya incluido una cláusula compromisoria, el alcance subjetivo del acuerdo solamente permite inferir la voluntad de las partes de someterse a un arbitraje individual y regido por el trámite normalmente aceptado para todo trámite arbitral. Por ello, para que proceda la acción de clase por medio de arbitraje será necesario que exista una redacción especialmente amplia que permita inferir que las partes así lo quisieron. De lo contrario, no habrá arbitraje de clase, y cada individuo deberá iniciar un arbitraje independiente.

Por otra parte, en tratándose de controversias societarias, al existir unos únicos estatutos sociales en los cuales la redacción típica de la cláusula compromisoria (del tipo "cualquier controversia entre los accionistas y la sociedad, o de los accionistas entre sí, será resuelta por medio de arbitraje") es perfectamente posible tramitar acciones de clase por medio de arbitraje, pues el alcance subjetivo del acuerdo es perfectamente plurilateral ${ }^{24}$.

Sin embargo, la discusión se torna especialmente problemática en materia de controversias relativas a derechos de los consumidores en Colombia, pues en nuestro ordenamiento jurídico las cláusulas arbitrales en contratos de consumo se consideran como una "opción" a favor del consumidor, de conformidad con lo dispuesto en el artículo 80 del Decreto 1829 de 2013, por lo cual la compatibilidad de dicha disposición con el régimen de "opt out" consagrado en la Ley 472 de 1998 sobre acciones populares y de grupo queda en duda. Lo anterior, pues sería posible que determinados consumidores quedaran vinculados por un laudo, aunque no se hayan hecho parte del proceso, mientras que al mismo tiempo se estaría exigiendo a cada consumidor una acción positiva (demandar o hacerse parte del proceso) para quedar vinculado al acuerdo de arbitraje, lo cual es un contrasentido.

\section{2 ¿Cómo debe operar el principio de kompetenz-kompetenz?}

En relación al principio de kompetenz-kompetenz, nuestra legislación establece que, en materia de arbitraje doméstico:

24 Siendo consciente de lo anterior, la Institución Alemana de Arbitraje (DIS, por sus siglas en alemán), expidió unas Reglas Suplementarias para Controversias de Derecho Societario en el año 2009, las cuales se acercan considerablemente al arbitraje de clase. 
"El tribunal de arbitraje es competente para resolver sobre su propia competencia y su decisión prevalece sobre cualquier otra proferida en sentido contrario por un juez ordinario o contencioso administrativo. Lo anterior, sin perjuicio de lo previsto en el recurso de anulación.

Si del asunto objeto de arbitraje estuviere conociendo la justicia ordinaria o la contencioso administrativa, y no se hubiere proferido sentencia de única o primera instancia o terminado por desistimiento, transacción o conciliación; el tribunal arbitral solicitará al respectivo despacho judicial la remisión del expediente y este deberá proceder en consecuencia”.

Lo anterior significa, entonces, que corresponderá al tribunal arbitral determinar si tiene o no la competencia para resolver determinada controversia, para lo cual habrá de determinar si existe o no habilitación de las partes en tal sentido.

Ahora bien, ¿qué sucedería si los miembros de la clase o grupo deciden iniciar la acción colectiva ante los jueces ordinarios, alegando la ausencia de una base contractual suficiente que permita concluir que debe proceder el arbitraje de clase? Bajo la regulación del principio de kompetenz-kompetenz establecida en nuestro Estatuto Arbitral, aunque pueda resultar dilatorio, el juez tendría que remitir a las partes a arbitraje, pues no existe la posibilidad de efectuar una revisión prima facie del acuerdo arbitral en cuestión.

En México, por el contrario, la Corte Suprema de Justicia, sin invalidar expresamente los acuerdos arbitrales, sentó una excepción al principio de kompetenz-kompetenz, cuando quiera que exista un riesgo de eliminación de las acciones colectivas, que consideramos de difícil aplicación en Colombia teniendo en cuenta la regulación del arbitraje en contratos de adhesión (Decreto 1829 de 2013) y la estricta aplicación del principio de kompetenz-kompetenz (Arts. 29 y 70 del Estatuto Arbitral).

\section{3 ¿Es más eficiente tramitar una acción de clase ante un tribunal arbitral que ante un juez estatal?}

Bajo el caso Stolt-Nielsen, la existencia de una base contractual que permita inferir la voluntad de las partes de someterse a arbitraje de clase se fundamentó en un análisis especial que no se ha replicado en ninguna otra parte del mundo, a saber: la incompatibilidad de las acciones de clase y el arbitraje, en la medida en que las primeras harían de este un procedimiento engorroso, lento y con mayor intervención judicial.

En pocas palabras, la razón fundamental para exigir un consentimiento cualificado en materia de arbitraje de clase, se basa en la posibilidad de frustración de las expectativas de eficiencia procesal de las partes que han pactado arbitraje, a 
tal punto que el arbitraje ha llegado a ser considerado como el "peor Frankenstein de todos los mundos"25. Sin embargo, en Colombia, así como en otras partes del mundo, el análisis podría ser diferente, pues es posible que en distintas jurisdicciones sea más eficiente tramitar una acción de clase por medio de arbitraje que ante las cortes estatales.

El quid del asunto reside en que la regulación del arbitraje de clase en Estados Unidos complejiza en gran medida el proceso arbitral, tal y como puede evidenciarse en las Reglas Suplementarias para Arbitraje de Clase de la Asociación Americana de Arbitraje, las cuales establecen el siguiente procedimiento tripartito:

1. Fase de interpretación del acuerdo arbitral, en la que el tribunal expide un laudo arbitral parcial mediante el cual determina si los acuerdos arbitrales en cuestión permiten o no el arbitraje de clase.

2. Fase de certificación de la clase, en la que el tribunal arbitral expide un laudo arbitral parcial mediante el cual determina si se cumplen o no los requisitos establecidos en la ley para la procedencia de una acción de clase.

3. Fase final, en la que el tribunal arbitral resuelve los méritos de la controversia mediante un laudo final.

Entre cada una de las fases anteriormente citadas, el tribunal arbitral deberá suspender el procedimiento por al menos treinta (30) días para que las partes busquen la confirmación o anulación del laudo arbitral ante las cortes estatales, lo cual como es natural prolonga en gran medida en proceso arbitral y lo hace menos eficiente.

No obstante, dicho esquema regulatorio no necesariamente debe seguirse en otras partes del mundo, siendo perfectamente posible adoptar una regulación mucho más eficiente que permita resolver con prontitud la controversia colectiva.

Resalta, particularmente, la decisión del tribunal arbitral en el caso Luis Alberto Durán v. Bancolombia, el cual se vio abocado a un problema de tipo procesal especial, dada la ausencia de unas reglas especiales en materia de arbitraje de clase como las establecidas en distintos centros de arbitraje en Estados Unidos, por lo cual el tribunal arbitral tuvo que determinar bajo qué normas sería tramitado el proceso dada la confluencia de las normas procedimentales que regulan el trámite arbitral y las normas que regulan el trámite de las acciones de grupo.

25 Estados Unidos. Corte de Apelaciones para el Onceavo Circuito. Marriott Ownership Resorts, Inc; Marriott Vacations Worldwide Corporation; Marriott Resorts, Travel Company, Inc.; Marriott Resorts Hospitality Corporation v. William B. Sterman. Brief of the Chamber of Commerce of the United States of America as Amicus Curiae in support of plantiffs-appelants. No. 15-10627. 
De forma salomónica, el tribunal arbitral en cuestión consideró que, en la medida en que la habilitación de los árbitros se realizó, de acuerdo con la Constitución Política, "en los términos de la ley", era la ley la que determinaba que las normas especiales en materia de arbitraje serían las aplicables, siendo necesario aplicar en el caso concreto igualmente algunas normas especiales y garantías propias de las acciones de grupo, tales y como: (i) normas sobre integración del grupo y ejercicio del derecho de "opt out"; (ii) normas sobre la audiencia de conciliación en materia de acciones de grupo, y (iii) normas especiales sobre contenido de la decisión judicial, de acuerdo con las reglas especiales de acciones de grupo ${ }^{26}$.

Con ello, el trámite de la acción de grupo se benefició del esquema procesal especial, la celeridad y especialidad del arbitraje, razón por la cual después de haber sido proferida la sentencia de la Corte Suprema de Justicia de Colombia, el laudo arbitral mediante el cual se resolvía definitivamente la controversia fue dictado en cerca de dos años y medio, siendo este un término de tiempo considerablemente menor al tiempo que posiblemente hubiera tomado el trámite de la acción de grupo ante los jueces ordinarios.

\section{Conclusiones}

El arbitraje de clase es una modalidad especial de arbitraje que genera una discusión bastante enriquecedora a partir de la cual se puede evidenciar con claridad la naturaleza dual (contractual-procesal) del arbitraje, y en cuyo análisis confluyen elementos tanto de eficiencia procesal, de acceso a la administración de justicia y naturalmente del consentimiento otorgado por las partes.

Si bien es cierto que, normalmente, las partes que celebran un acuerdo arbitral no vislumbran que sus controversias pueden eventualmente ser resueltas de forma colectiva, junto con cientos o incluso miles de individuos con los que no existió ningún tipo de interacción, bajo ciertas circunstancias es perfectamente posible que así suceda.

Confiamos, de esta forma, en que los análisis realizados servirán para resolver satisfactoriamente los futuros casos que se presenten en Colombia y en otras partes del mundo.

26 Colombia. Tribunal de Arbitramento Luis Alberto Durán Valencia v. Bancolombia S.A., Portafolio de Inversiones Suramericana S.A., Cementos del Valle S.A., Compañía Colombiana de Tabaco S.A., Compañía de Cementos Argos S.A., Inversiones Reacol S.A., Compañía Suramericana de Seguros S.A. y Suramericana de Inversiones S.A. Auto No. 7 del 28 de febrero de 2003.

ISSN 2346-3473 • pp. 229-248 • Julio - Diciembre de 2017 • Bogotá, D.C. - Colombia 
Las acciones de grupo y el arbitraje: un dilema entre consentimiento y eficiencia procesal

\section{Referencias bibliográficas}

\section{Doctrina}

GUTH BARNES. Lauren. "How mandatory arbitration agreements and class action waivers undermine consumer rights and why we need congress to act". En: Harvard Law \& Policy Review. Vol. 9. No. 1. Cambridge: Estados Unidos, 2015, pp. 329-354.

STRONG, Stacie. "Collective arbitration under the DIS supplementary rules for corporate law disputes”. En: ASA Bulletin. Vol. 29. No. 1. Ginebra: Asociación Suiza del Arbitraje, 2011, pp. 145-165.

\section{Jurisprudencia}

Colombia. Corte Suprema de Justicia. Sentencia del 11 de mayo de 2011. Exp. 1100122030002001-0183-01. MP. Carlos Ignacio Jaramillo Jaramillo.

Colombia. Tribunal de Arbitramento Luis Alberto Durán Valencia v. Bancolombia S.A., Portafolio de Inversiones Suramericana S.A., Cementos del Valle S.A., Compañía Colombiana de Tabaco S.A., Compañía de Cementos Argos S.A., Inversiones Reacol S.A., Compañía Suramericana de Seguros S.A. y Suramericana de Inversiones S.A. Auto No. 3 del 17 de febrero de 2003.

Colombia. Tribunal de Arbitramento Luis Alberto Durán Valencia v. Bancolombia S.A., Portafolio de Inversiones Suramericana S.A., Cementos del Valle S.A., Compañía Colombiana de Tabaco S.A., Compañía de Cementos Argos S.A., Inversiones Reacol S.A., Compañía Suramericana de Seguros S.A. y Suramericana de Inversiones S.A. Auto No. 7 del 28 de febrero de 2003.

Estados Unidos. Corte de Apelaciones para el Onceavo Circuito. Marriott Ownership Resorts, Inc; Marriott Vacations Worldwide Corporation; Marriott Resorts, Travel Company, Inc.; Marriott Resorts Hospitality Corporation v. William B. Sterman. Brief of the Chamber of Commerce of the United States of America as Amicus Curiae in support of plantiffs-appelants. No. 15-10627.

Estados Unidos. Corte Suprema de Justicia. Green Tree Financial Corp. v. Bazzle. 23 de junio de 2003. No. 02-634.

Estados Unidos. Corte Suprema de Justicia de California. Keating v. Superior Court. 10 de junio de 1982. 31 Cal. 3d 584.

Estados Unidos. Corte Suprema de Justicia. Oxford Health Plans LLC v. Sutter. 10 de junio de 2013. No. 12-135.

Estados Unidos. Corte Suprema de Justicia. Stolt-Nielsen, et. al. v. AnimalFeeds. 27 de abril de 2010. No. 08-1198.

Estados Unidos. Corte Suprema Justicia de Carolina del Sur. Lynn W. Bazzle and Burt A. Bazzle, in a representative capacity on behalf of a class and for all others similarly situated v. Green Tree Financial Corp. - Daniel B. Lackey, George Buggs and Florine Buggs, in a representative capacity on behalf of a class and for all others similarly situated v. Green Tree Financial Corp. 26 de agosto de 2002. No. 25523.

México. Corte Suprema de Justicia de la Nación. Amparo directo 33/2014. 24 de septiembre de 2014. 